\title{
Climate policy through changing consumption choices: Options and obstacles for reducing greenhouse gas emissions
}

\author{
Bastien Girod ${ }^{\text {a,b,* }}$, Detlef Peter van Vuuren ${ }^{\text {b,c }}$, Edgar G. Hertwich ${ }^{\text {d }}$ \\ a Swiss Federal Institute of Technology Zurich (ETH Zurich), Department of Management, Technology, and Economics, Chair of Sustainability and Technology, \\ Weinbergstrasse 56, 8032 Zurich, Switzerland \\ ${ }^{\mathrm{b}}$ Copernicus Institute of Sustainable Development, Utrecht University, Heidelberglaan 2, 3584 CS Utrecht, The Netherlands \\ ${ }^{\mathrm{c}}$ PBL-Netherlands Environment Assessment Agency, P.O. Box 1, 3720 BA Bilthoven, The Netherlands \\ ${ }^{\mathrm{d}}$ Industrial Ecology Program and Department of Energy and Process Engineering, Norwegian University of Science and Technology, 7491 Trondheim, Norway
}

\section{A R T I C L E I N F O}

\section{Article history:}

Received 18 October 2013

Received in revised form 25 December 2013

Accepted 6 January 2014

Available online 1 February 2014

\section{Keywords:}

Sustainable consumption

Climate policy

Life-cycle assessment

RCP2.6 climate target

Behavioral economics

\begin{abstract}
A B S T R A C T
While national climate policy can address countries' production or consumption, climate mitigation via changes in consumption has previously received relatively little attention in climate policy literature. In the absence of an effective international climate policy, the focus on consumption is gaining relevance since it has advantages regarding carbon leakage and competitiveness concerns. In addition, consumption oriented climate policy allows for low cost climate mitigation because of behavioral market failures. Therefore, a systematic evaluation of low greenhouse gas consumption options is needed. This article reviews the carbon footprint of products in the five main consumption categories (food, shelter, travel, goods and service) and compares their compatibility with the greenhouse gas intensity required in 2050 to meet the $2^{\circ}$ climate target. The evaluation then identifies consumption options compatible with this climate target in all categories. The description of these consumption options allows for the recognition of barriers to their selection. In contrast to production oriented climate policy, besides costs, relevant barriers include consumer preferences, the skills required to find or adopt the product and high initial investments. We conclude that there is substantial climate mitigation potential from changing consumption choices which can be tapped through climate policy by addressing non-cost barriers.
\end{abstract}

(c) 2014 Elsevier Ltd. All rights reserved.

\section{Introduction}

To avoid dangerous levels of climate change, nearly all countries subscribed, in the Copenhagen Protocol and the subsequent Cancun Agreement, to limit global average temperature rise to no more than $2^{\circ}$ compared to preindustrial levels (UN, 2011). Of the Representative Concentration Pathways (RCP) evaluated by the IPCC (van Vuuren et al., 2011a), only the lowest pathway, the RCP2.6 (van Vuuren et al., 2011b), is consistent with this climate target (Meinshausen et al., 2011).

In the past, climate policy and research has mostly focused on approaches that relate greenhouse gas emissions to production. This is apparent from the greenhouse inventories which categorize

\footnotetext{
* Corresponding author at: Swiss Federal Institute of Technology Zurich (ETH Zurich), Department of Management, Technology, and Economics, Chair of Sustainability and Technology, Weinbergstrasse 56, 8032 Zurich, Switzerland. Tel.: +41446326313.

E-mail address: bgirod@ethz.ch (B. Girod).
}

emissions from a territorial, and hence production, perspective (Peters and Hertwich, 2008). This approach corresponds well to the underlying assumption that countries are responsible for the emissions within their territory. One advantage of this approach is that it is methodologically more straightforward to assign emissions on the basis of their geographical location (thus related to production) (Peters and Hertwich, 2008). Policies promoting innovation and deployment of low carbon technologies also tend to favor production compared to end-use energy technologies (Wilson et al., 2012). Studies evaluating the feasibility of the RCP2.6 have typically used a modeling approach, in which a carbon tax is introduced, and most often these models tend to be much more detailed on production activities than on consumption (e.g. Vuuren et al., 2011).

While a production-oriented perspective has its advantages, it also has clear limitations. At the moment, ambitious climate policies via the UN Framework Convention on Climate Change seem impossible before 2020 (Jacobs, 2012). This means that strengthening current policies relies mostly on a climate "coalition of the willing" formed by countries, cities and citizens (Schnoor, 
2012). For such a coalition, the consumption perspective can be more attractive for at least three different reasons: embodied emissions, economic competitiveness, and behavioral market failures. First, contrary to the production perspective, the consumption perspective includes the embodied emissions (Peters and Hertwich, 2006). It is more effective in avoiding carbon leakage (Böhringer et al., 2012) and extending the influence of the "coalition of the willing" to the production of imported products. The consumption perspective is relevant because this coalition typically represents entities such as cities, which show rather high tertiary sector activity and import a relevant share of products responsible for greenhouse gas (GHG) emissions (Larsen and Hertwich, 2009). Second, policies oriented toward changes in consumption choices have a lower effect on international competitiveness, because they do not affect the cost of exported products and equally affect products in the home market, whether imported or produced locally. In contrast, production side policies can lead to a disadvantage for domestic industry on the home market, as well as on foreign markets, according to theoretical and empirical finding of the OECD (2007). Model simulations show possible disadvantages of unilateral environmental taxes on industry, and a policy survey shows that environmentally related taxes are levied almost exclusively on households and the transport sector. The producing sector (industry) is usually exempted due to competitiveness concerns. The ineffectiveness of unilateral, domestically oriented climate policies in reducing emissions from the production of energy-intensive goods has been confirmed by international energy modeling forums (Böhringer et al., 2012). Third, findings from behavioral economics emphasize the important role of behavioral market failures (e.g. underestimation of energy efficiency savings) representing barriers to the adoption of low GHG consumption options (Gillingham and Sweeney, 2012). Adjustment in the choice architecture of consumers (e.g. default products, information, standards) can therefore provide climate mitigation potential at low or even negative costs (Allcott and Mullainathan, 2010). Examples of measures allowing for negative costs are increases in energy efficiency through labels indicating the lower energy costs for more efficient cars, or building codes requiring economically optimal levels of insulation (Dietz et al., 2009; Sunstein, 2013).

Despite the increasing support for consumption oriented climate policy, little research is available on its climate mitigation potential. Studies have evaluated the potential for changes in consumption patterns for single sectors, such as food (Stehfest et al., 2009a) or passenger transportation (Girod et al., 2013a). However, by focusing on a single sector they do not provide the full picture across the different consumption categories. A broader focus was applied by Dietz et al. (2009). They evaluate the potential of a selection of 17 household action types, including changes in purchase as well as the use of energy consuming appliances, focusing on the GHG emissions resulting from direct energy consumption at home or through personal vehicles. We contribute to this literature by combining the broader evaluation across consumption categories with a global perspective including emissions embodied in non-energy goods. Since changes in the purchase of climate friendly products show broader acceptance compared to life style changes (Dietz et al., 2009; Tobler et al., 2012), we focus on the former and evaluate the difference in the GHG emissions of consumption options.

In earlier work we developed a concept to translate global climate policy targets to the consumption level (Girod et al., 2013b). This concept is applied to identify consumption options in line with the international climate target (RCP2.6). This article extends the previous work by evaluating a broad range of products through a review of life-cycle assessment studies in the consumption categories of food, shelter, travel, goods and services.
This allows for a direct quantitative comparison of different consumption items with the required GHG intensity for the $2^{\circ}$ climate target. In this way, it is possible to identify various low GHG options consistent with the $2^{\circ}$ target across all consumption categories. As a final step we discuss the barriers to low GHG consumption based on these options and derive implications for climate policy aimed at changing consumption choices.

The article is organized as follows: first, we give a overview on levers for climate mitigation and position the evaluated demand side strategy relative to other strategies (Section 2). Next, we present the method used to evaluate the climate mitigation potential of changes in consumption choices (Section 3). In Section 4 we present and identify low GHG consumption options in line with the $2^{\circ}$ climate target. On this basis, we discuss barriers to the low GHG options and draw policy implications. Finally, we present our conclusions on climate policy through changing consumption choices (Section 5).

\section{Scope: overview on climate mitigation strategies}

In this section we give a systematic overview of possible strategies to lower GHG emissions by applying the IPAT equation (Commoner and Corr, 1971; Ehrlich et al., 1971). This allows us to clarify the scope of this article. Using 'GHG emissions' to specify the environmental impact, 'consumption per capita' to represent the affluence and 'GHG emissions per unit of consumption' to describe the technology, the global emissions can be decomposed according to the IPAT equation:

$$
\begin{aligned}
\underbrace{\text { GHG Emissions }}_{\text {Impact }} \text { Em }_{c}= & \text { Population } \\
& \cdot \underbrace{\frac{\text { Consumption }}{\text { Capita }}}_{\text {Affluence }} \cdot \underbrace{\frac{G H G \text { Emissions }_{c}}{\text { Consumption }}}_{\text {Technology }}
\end{aligned}
$$

Consumption can be divided into different categories, $c$, or even further disaggregated to the different product and service items, $i$. By replacing the consumption, Consumption ${ }_{c}$, with production, Production $_{c}$, this equation can also be applied to evaluate emissions reduction from a production perspective. We differentiate the strategies to lower global GHG emissions by the term of the GHGIPAT equation which they address. Depending on whether consumption is measured in monetary units or physical units, further strategies can be differentiated. An overview of these strategies and corresponding examples from literature is given in Table 1. In this article we focus on low GHG consumption, which includes the choice of similar but less GHG intensive products (changing patterns) or the same product produced with less GHG emissions (product improvement).

Since there is not always a clear line between the different strategies, we describe the similarities and differences between the evaluated low GHG consumption strategies and the rest. With the rather broad categories applied in this study (food, shelter, travel, goods, services), changes within consumption categories are in some cases (e.g. dietary changes) similar to lifestyle changes. The difference to lifestyle change is determined by the definition of the main consumption categories. The reduction of the consumption of a certain GHG intensive product (e.g. car use) is also similar to the sufficiency strategy. However, in contrast to sufficiency and lifestyle change, in the low GHG consumption strategy, the amount of eating, traveling and shopping remains the same but alternative low GHG options are chosen instead of GHG intensive products. The similarity to the low GHG user behavior strategy is that neither changes the consumption level. However, low GHG behavior focuses on changing the use of the same product (e.g. driving a car more gently) rather than choosing an alternative 
Table 1

Overview and examples of possible mitigation strategies following the IPAT equation.

\begin{tabular}{|c|c|c|}
\hline Climate change mitigation strategy & GHG-IPAT variable & Examples from literature \\
\hline Smaller population & Population & $\begin{array}{l}\text { The "people and the planet" report (Sulston et al., 2012) concludes that } \\
\text { global population growth needs to be slowed and stabilized and identifies a } \\
\text { large unmet need for contraception }\end{array}$ \\
\hline Sufficiency & $\frac{\text { Consumption }}{\text { Captia }}$ & $\begin{array}{l}\text { Jackson (2009) argues for a redefinition of "prosperity" in light of the } \\
\text { evidence on what really contributes to people's wellbeing and to abandon } \\
\text { the current income maximization strategy }\end{array}$ \\
\hline Better instead of more & & $\begin{array}{l}\text { Girod and de Haan (2010) show that even without decreasing income, } \\
\text { purchasing high quality and environmentally friendly products reduces GHG } \\
\text { emissions by decoupling physical consumption and income }\end{array}$ \\
\hline New lifestyle & $\frac{\text { Consumption }_{\text {category }}}{\text { Capita }}$ & $\begin{array}{l}\text { The IPCC SRES B1 scenario describes lifestyle changes shifting consumption } \\
\text { across categories from energy intensive consumption (e.g. transportation) to } \\
\text { service oriented economy (de Vries et al., 2000; IPCC, 2000) }\end{array}$ \\
\hline \multicolumn{3}{|l|}{ Focus of this study } \\
\hline Low GHG consumption (changing patterns) & $\frac{\text { Consumption }_{\text {item }}}{\text { GHG }}$ & $\begin{array}{l}\text { Shift in consumption pattern without changes in consumption level, such as } \\
\text { changes in diets (Stehfest et al., 2009a), travel modes (Girod et al., 2012) or } \\
\text { expenditure (Alfredsson, 2004) }\end{array}$ \\
\hline Low GHG consumption (product improvement) & $\frac{\text { GHG Emissions } \text { Eategory }^{\text {Consumption }} \text { category }}{\text { Cor }^{2}}$ & $\begin{array}{l}\text { Buying the same item - no change in consumption pattern - but selecting a } \\
\text { variant with lower GHG intensity, e.g. solar house (Bojić et al., 2011) or } \\
\text { electric car (Hawkins et al., 2013) }\end{array}$ \\
\hline Low GHG user behavior (product use) & $\frac{\text { GHG Emissions }_{\text {item }}}{\text { Consumption }_{\text {item }}}$ & $\begin{array}{l}\text { Changing the use of already purchased products like lowering the } \\
\text { temperature for a washing machine or water heater or changing driving } \\
\text { behavior (Dietz et al., 2009) }\end{array}$ \\
\hline Low GHG production & $\frac{\text { GHG Emissions }_{\text {item }}}{\text { Production }_{\text {item }}}$ & $\begin{array}{l}\text { Supply side measures like cleaner manufacturing processes, e.g. by using } \\
\text { CCS, renewable energies or increasing efficiency in production. Dominant } \\
\text { strategy in global climate mitigation models (e.g. van Vuuren et al., 2011b) }\end{array}$ \\
\hline
\end{tabular}

product (e.g. buying a more efficient car). We exclude low GHG user behavior from our study because its mitigation potential depends on the product itself. For instance, the potential of lowering energy use through gentle driving depends on the efficiency of the car. Typically, the potential of low GHG user behavior decreases with low GHG products. Evaluating these options and accounting for such interdependencies would go beyond the scope of this article. Some low GHG consumption strategies also overlap with the low GHG production or 'better instead of more' strategies. The well-known example of organic food shows that consumers can, with the aid of labels, choose identical products which are produced in a different manner. Labels allowing consumers to recognize low GHG production are less widespread, however first labels on products indicating the use of renewable energy in production are available (Brannan et al., 2012). We will therefore also include an evaluation of the GHG emissions of different power supply options in our evaluation. Finally, when low GHG products have higher quality and price, low GHG consumption can overlap with the "better is more" strategy. However, we do not take into account a reduction in consumption level due to higher expenditure for more expensive products.

Carbon offsetting is not considered in Table 1 or in our study because it does not actually change consumption. Still, it can be an effective strategy to finance low GHG production through the consumer and is also increasingly used, not only for compensating air travel emissions, but also as a voluntary measure from retailers (Lovell et al., 2009).

\section{Method: Assessing changing consumption choices}

This section focuses on the method used to evaluate the climate mitigation potential of choosing climate friendly products (low GHG consumption). We start with the description of the consumption categories and corresponding consumption units. Next, we describe how the GHG emissions of different consumption options are reviewed to identify illustrative consumption options. Finally, the global GHG emission targets on the production level for 2050 in line with the RCP2.6 ( $2^{\circ}$ climate target) are described.

\subsection{Consumption categories}

To compare the GHG emissions of different consumption options, a life-cycle assessment approach is required. A life-cycle assessment includes all emissions from the cradle to the grave of a product. In life-cycle assessment, functional units are used to define the quantified performance of a product system (ISO, 2006). These functional units are the basis for comparing the GHG emissions of different products. Accordingly, we describe the consumption per capita in functional units.

For our analysis, we select five different consumption categories reflecting the different basic needs; namely, food, shelter, mobility, goods and services. This categorization can be related to the Classification of Individual Consumption According to Purpose from the United Nations Statistics Division (United Nations Statistics Division 2008). In general, we use a strict life cycle perspective, with two exceptions made in order to avoid double accounting. All energy use at home is allocated to shelter. Hence, food preparation at home (e.g. cooking) and use of electronic goods (e.g. TV) are included. All appliances bought separately from the house are allocated to goods, even though they might be used to prepare food or provide living comfort. Since electricity consumption is highly relevant for GHG emissions and, in many countries, households have the possibility to choose their electricity, we add electricity consumption as a sixth category into our evaluation. However this category - in contrast to other categories - is not an end but a means for consumption. This pragmatic implementation of the consumption categories was also guided by the available data.

Each of these categories can be described with different consumption units. The demand for food is described by its energy content in calories, in line with the World Food and Agriculture Organization, FAO (2006). For shelter, the floor space is commonly used as a reference for consumption (IIASA, 2012). Travel demand is typically described in person kilometers (pkm) (Girod et al., 2013c). For goods and services, determining functional units is more ambiguous. The weight in kilograms and monetary value in US dollars, respectively, are typically used in studies on the environmental impact of goods and services (Girod and de Haan, 2010; Hendrickson et al., 1998). These, however, do 
not capture the broad range of functionalities in these consumption categories. Finally, for power supply the unit is $\mathrm{kWh}$.

Using the same consumption unit within the five categories neglects other functional dimensions. Hence, a shift within a consumption category can go along with changes in functionality, which might reduce the substitutability of consumption options. We will discuss this limitation with the results.

\subsection{Illustrative consumption options}

We now look at possible GHG relevant choices in the different consumption categories by looking at the most widely consumed product for each consumption category (default option) and alternative products allowing a significant decrease in GHG intensity. We refer to these as illustrative consumption options. A third category of illustrative options are those that could increase GHG intensity and that are likely to increase in share. The illustrative consumption options are selected on the basis of a review of the GHG emissions of products in the different consumption categories and power supply. We consider only products which are available to consumers, at least in niche markets today, hence excluding possible future innovations. This scope fits with the coverage of life-cycle assessment studies, as they typically evaluate existing products and related processes.

To identify relevant consumption options, life-cycle assessment data was accessed mainly via the SimaPro life-cycle assessment software (v.7.1.0). This allowed access to data (number of data sets used are indicated in brackets) for travel (14), goods (14) and power (21) from the ecoinvent data (Frischknecht and Rebitzer, 2005), for food (15) from the Danish food life-cycle assessment database (Nielsen et al., 2003) and for services (10) from the Danish-European and the US environmental input-output databases (Suh, 2005). This first dataset was complemented by peerreviewed studies on product life-cycle assessment in the five consumption categories, resulting in further data for food (17 from Carlsson-Kanyama and González, 2009 and 18 from González et al., 2011), conventional transport vehicles (11) (Chester and Horvath, 2009) and electric vehicles (4) (Hawkins et al., 2013). Shelter data that includes embodied emissions was not available from the SimaPro datasets. In peer-reviewed journals, only the study from Dahlstrøm et al. (2012) was found which provided data for new buildings in Norway (8). Therefore for this category a report from the Swiss federal office (Dettli et al., 2006) on life-cycle emissions of new buildings with different efficiency standards was also considered (5). Emissions for old buildings had to be estimated based on direct energy use and estimates for embodied emissions (Harvey, 2009; IIASA, 2012). A detailed description of the reviewed consumption options is provided with the supplementary information (Table S1).

\subsection{GHG intensity targets}

Global climate targets for the year 2050 can be translated to the consumption level. First, global consumption levels for the different consumption categories are projected for 2050. The global average consumption per capita in the Business as Usual (BaU) is projected to continue to increase similar to past trends, with service expenditure and travel demand closely following the GDP per capita, while goods and shelter consumption decouple and food shows the highest saturation (see Fig. 1). Second, the RCP2.6 emissions for 2050 are translated into 2.1 ton $\mathrm{CO}_{2} \mathrm{e}$ per capita, based on the population size expected for 2050 (9.1 billion persons). The per capita emissions are then allocated to the different consumption categories. In Table 1 the allocation considers the consumption trends until 2050. Third, the GHG intensity results from the division of the allowable emissions by the corresponding global consumption levels. A detailed description of this method is provided by Girod et al. (2013b). Key results are provided in Table 2.

Girod et al. (2013b) evaluated alternative allocation methods as well as higher and lower projections of consumption levels. The alternative allocation includes a distribution according to the emission distribution in 2000 (because policy often refers to past emission levels to allocate mitigation reduction) and according to the mitigation costs for the different categories. This resulted in a range of global GHG intensity targets for comparison with the GHG intensity of the different consumption options as reported in the last column of Table 2 .

Since this concept applies to consumption categories related to the basic needs, electricity consumption is allocated to shelter (heating, cooking, appliances, lighting etc.) and mobility (electric vehicle, trains), as well as the production of food, goods and services, but has no proper GHG intensity target.

\section{Results and discussion}

We first present the evaluation and identification of low GHG consumption options. Next, relevant barriers to the low GHG options and possibilities to overcome them are discussed. Finally, we reflect on limitations and further research.

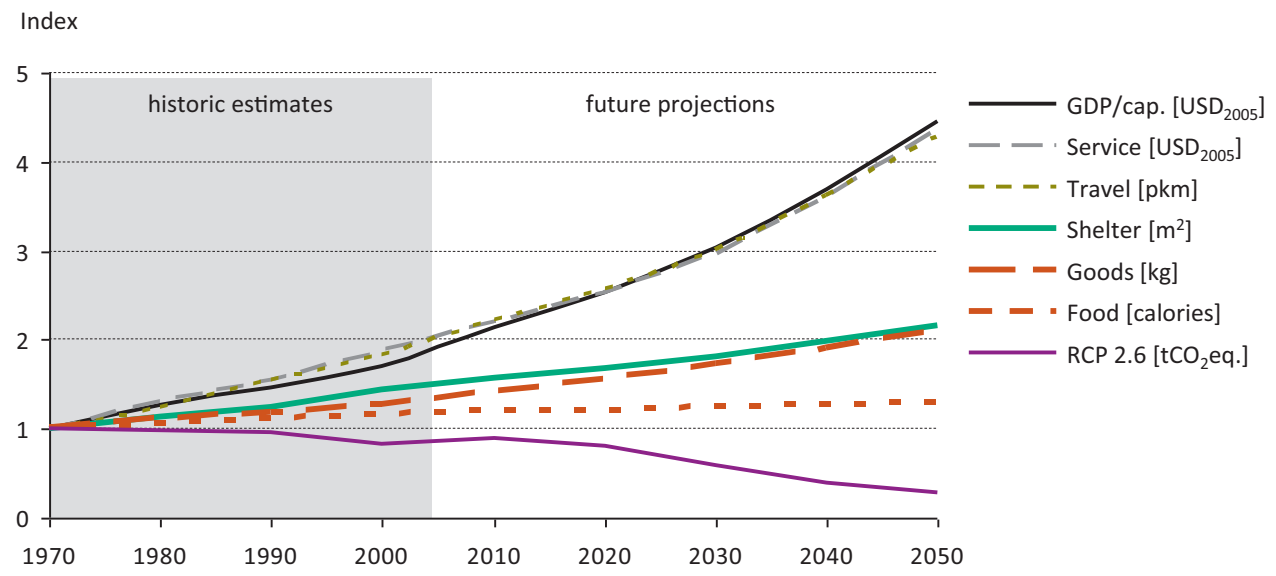

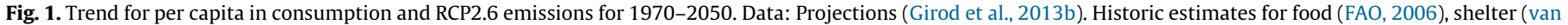

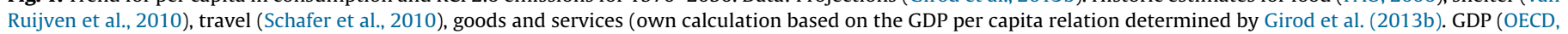
2011). RCP2.6 based on Meinshausen et al. (2011) and the UN medium population projection (UN, 2009). 
Table 2

Global consumption, GHG emissions and GHG intensity for the different consumption categories in 2010 and 2050.

\begin{tabular}{|c|c|c|c|c|c|c|c|c|}
\hline \multicolumn{2}{|c|}{ Consumption category } & \multicolumn{2}{|c|}{$\begin{array}{l}\text { Global consumption (A) } \\
\text { [unit/cap] }\end{array}$} & \multicolumn{2}{|c|}{$\begin{array}{l}\text { Global GHG emissions (B) } \\
{\left[\mathrm{tCO}_{2} \mathrm{e} / \mathrm{cap}\right]}\end{array}$} & \multicolumn{3}{|c|}{$\begin{array}{l}\text { GHG intensity }(\mathrm{A} / \mathrm{B}) \\
{\left[\mathrm{kgCO}_{2} \mathrm{e} / \text { unit }\right]}\end{array}$} \\
\hline & \multirow[t]{2}{*}{ Unit } & \multirow[t]{2}{*}{2010} & 2050 & 2010 & 2050 & 2010 & 2050 & \\
\hline & & & \multicolumn{2}{|l|}{$\mathrm{BaU}$} & \multicolumn{2}{|l|}{$\mathrm{RCP} 2.6^{\mathrm{a}}$} & \multicolumn{2}{|c|}{ RCP2.6, global ${ }^{\mathrm{b}}$} \\
\hline Food & Mcal & 1048 & 1131 & 1.5 & 0.4 & 1.4 & 0.37 & $0.3-0.6$ \\
\hline Shelter & $\mathrm{m}^{2}$ year & 21 & 29 & 0.7 & 0.2 & 31.9 & 5.6 & 5-11 \\
\hline Travel & $1000 \mathrm{pkm}$ & 6.5 & 12.6 & 1.7 & 0.7 & 255 & 53 & $34-62$ \\
\hline Goods & $\mathrm{kg}$ & 278 & 410 & 1.0 & 0.4 & 3.6 & 1.0 & $0.6-1.0$ \\
\hline Services & USD & 1830 & 3613 & 1.1 & 0.4 & 0.6 & 0.12 & $0.07-0.14$ \\
\hline Total & & & & 6.0 & 2.1 & & & \\
\hline
\end{tabular}

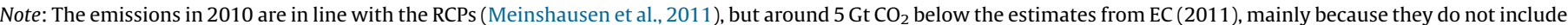
the LULUCF emissions. However, these emissions are projected to decline in all RCP scenarios by 2050 (Vuuren et al., 2011).

a Allocation to consumption categories according to the projected distribution in 2050 .

b Mean value for allocation according to the projected distribution in the year 2050, for the range different allocation and income projections from Girod et al. (2013b). Source: (Girod et al., 2013b).

\subsection{GHG intensity of consumption options}

Fig. 2 combines the categories, illustrative consumption options and GHG intensity target as described in the method section. Where several estimates were found in literature for one consumption option (e.g. different values for GHG emissions from vegetables), we indicate the mean value as well as the minimum and maximum value. In the following, for each of the five consumption categories and power supply, we describe the illustrative options. Then we explain the differences in their GHG intensity and compare them to the GHG intensity target for 2050. Finally, we validate the identified low GHG consumption options through comparison with studies from literature using different approaches.

\subsubsection{Food}

In general non-vegetal foodstuffs have higher emissions per calories than vegetal foodstuffs. But vegetal food can also result in very high GHG intensity if transported by air or grown in heated and artificially illuminated greenhouses. Within the non-vegetal food category, ruminant meat (e.g. beef) has around 10 times higher GHG intensity than dairy products or non-ruminant meat like chicken or pork. Protein-rich vegetables like soy and peas are in line with the GHG intensity target.

The high GHG intensity of non-vegetal foodstuffs results to an important amount from non-fossil GHG emissions, mostly nitrous oxide and methane. Methane is produced through the decomposition of manure (urine and feces) and the enteric fermentation during digestion from herbivores and most ruminants (CarlssonKanyama and González, 2009). The latter explains the higher GHG intensity for ruminant meat. For vegetal foodstuffs, GHG emissions mainly stem from energy use in farming, transportation and preparation of the food. The exceptional impact of air travel can be explained by the 150 times higher $\mathrm{CO}_{2}$ emissions per ton kilometer for airfreight compared to ocean freight (Frischknecht and Rebitzer, 2005). Other transport modes are less efficient than shipping but typically cover significantly shorter distances. The high GHG intensity for vegetables grown in heated greenhouses is not surprising if the inefficiency of heating the barely insulated greenhouses is considered.

Considering the different GHG intensities, three low GHG consumption options can be identified: increase vegetal foodstuffs (e.g. soy based meat substitutes like tofu or more vegetable menus), avoid vegetables transported by air or from heated greenhouses and focus on non-ruminant meat instead of ruminant meat (e.g. pig and chicken instead of beef). These low GHG options are in line with the global assessment of diet changes, finding that a shift to a low-meat diet (including less ruminant meat, less meat and less animal products) would reduce the cost of achieving a $450 \mathrm{ppm} \mathrm{CO}_{2}$-eq. stabilization target by about 50\% (Stehfest et al., 2009b).

\subsubsection{Shelter}

The shelter category includes all emissions from energy used in the building, as well as for the construction of the building itself. For shelter, old buildings typically result in the highest GHG intensity. In comparison newly constructed buildings emit half the amount. Further reductions in GHG intensity are possible with high efficiency buildings. However, only when using renewable energy for heating, hot water and appliances the GHG intensity target is met. Retrofitting to the same energy efficiency level allows for even lower GHG intensity.

The GHG intensities can be explained by the $\mathrm{CO}_{2}$ emissions from heating, which are mainly reduced by better insulation. Ventilation with heat recovery and efficient appliances further reduce energy use. Even more important than energy efficiency is the carbon intensity of the energy carrier. This explains the large range of GHG intensities for new buildings using different electricity mixes, and the drop in emissions from using electricity explicitly from renewables. For efficient buildings using renewable energy, the embodied emissions from building materials contribute to more than half the total GHG emissions. These embodied emissions explain why retrofitted building with the same efficiency level result in lower GHG intensity compared to new buildings.

The illustrative consumption options show that reaching the RCP2.6 target requires both increasing the energy efficiency and switching to renewable energy (e.g. wood pellets or electricity from hydro, wind or solar). To move toward the lower bound of the GHG intensity target, the embodied emissions need to be reduced by using existing construction (retrofit). In addition, recycling and alternative materials could allow the reduction of embodied emissions in buildings by around 15\% (Blengini, 2009; Thormark, 2006).

Even though the low GHG options are derived from a study for Swiss and Norwegian buildings, they are consistent with the global challenge. Globally, the largest contribution to shelter GHG emissions stems from heating, with the contribution of cooling being projected to increase rapidly because of the increasing use of air-conditioning (Isaac and van Vuuren, 2009). The main strategies to reduce GHG intensity remain valid for cooling: energy efficiency and renewable energy. Regarding the reduction potential, the global energy assessment draws a similar picture (IIASA, 2012). It states that due to recent advances in materials and know-how, final energy use for heating and cooling can be decreased by 60$90 \%$ for new buildings, and $50-90 \%$ for retrofits, with cost savings typically exceeding investments. Of course for building, and specifically heating, related energy use, the use behavior is also important. For instance, airing with tilt window can result in 

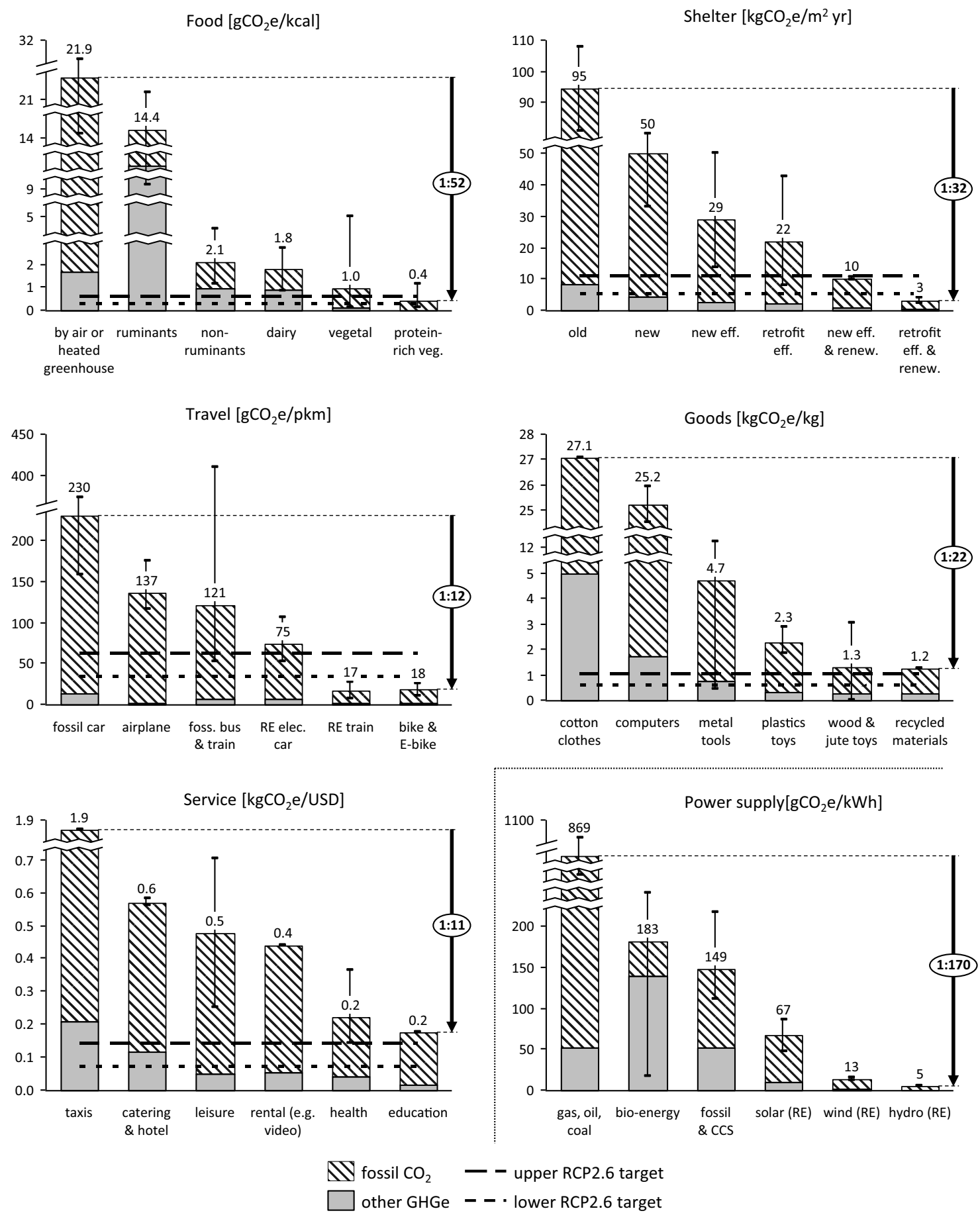

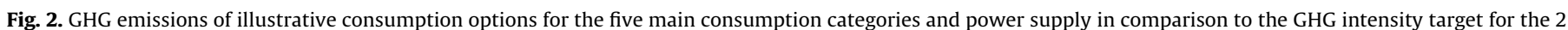

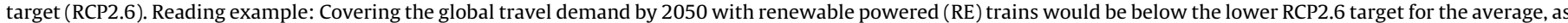

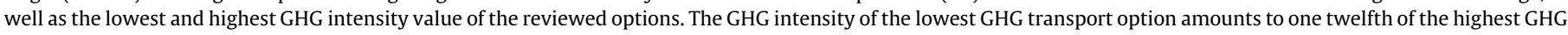

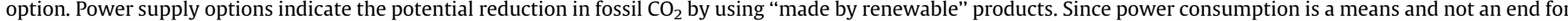
consumption, it has no GHG intensity target. For values for all options see Table S1.

significantly higher energy use. Since this is out of the scope (cf. Section2), we rely on standard behavior as assumed in the underlying studies.

\subsubsection{Travel}

The car and airplane are clearly above the GHG intensity target range. Fossil fueled public transport shows a range from the intensity of SUVs to the upper GHG intensity target. Renewable electric cars are around the upper target level. Renewable energy powered trains and e-bikes are even below the lower level.
The $\mathrm{CO}_{2}$ emissions related to the direct energy use explain the main difference in GHG intensity. For the electric vehicles, the emissions embodied in the vehicle and the batteries also become relevant. If electricity from fossil power plant is used, GHG emissions are similar to conventional gasoline cars (Hawkins et al., 2013). The emissions embodied in the car and batteries are estimated to be twice the emissions embodied in a conventional car. Hence, for an electric car using renewable power (e.g. wind), nearly $90 \%$ of the total GHG emissions stem from the production of the vehicle and battery (Hawkins et al., 2013). The high GHG 
intensity for fossil fuel public transport represents the value for a US diesel bus with very low passenger load (off-peak) (Chester and Horvath, 2009). This indicates that a certain settlement density is required to efficiently operate public transportation. The very low GHG intensity of public transport - as already observed today in countries like Switzerland (Spielmann and Scholz, 2005) - can be explained, not only by the low GHG intensity of the electricity, but by the high efficiency in energy use, vehicle and infrastructure use and related embodied emissions.

The resulting low GHG options include all renewable powered vehicles, especially trains and e-bikes. As airplanes cannot be fueled by renewables (hydrogen airplanes are not yet available and current biofuels have high embodied emissions), there is no low GHG air travel. A shift to high-speed trains can reduce at least emissions from continental flights. For international flights substitution is unfeasible. For some regions public transport might be difficult or inefficient because of scattered settlement, however here electric cars provide a low GHG option. Despite these limits in substitutability for air travel, the identified options are shown to be able to reduce GHG emissions according to the $2^{\circ}$ climate target by a global transport model (Girod et al., 2012).

\subsubsection{Goods}

Even if the six illustrative options represent only a small share of the possible goods and their materials, they illustrate the broad range of GHG intensities. High-tech products such as computers, but also natural products such as cotton, can result in very high GHG intensity. Basic metals and plastics show lower GHG intensity, with a wide range for metals. Recycled materials and natural products such as jute or wood are close to the GHG intensity target.

The emissions depend mainly on the energy intensity of the production and resource extraction process, which is very specific to the different goods. Low GHG consumption options are therefore possible by avoiding energy intensive production, by using natural products from extensive farming or by recycling materials. Reusing materials or extending the lifetime of materials requires even less energy compared to recycling of materials. The latter options are not displayed with the illustrative consumption option, but for non-energy-using goods such as clothing or furniture, the GHG intensity decreases linearly with the extended use phase.

The large difference in the energy intensity of goods is confirmed by input-output evaluations of household expenditures (Kok et al., 2006; Vringer and Blok, 1995). The environmental benefits from recycling, and even more so for reusing, are demonstrated for plastic-based packing systems (Ross and Evans, 2003). For recycling metals (aluminum and steel), a reduction by a factor four in GHG intensity was found (Damgaard et al., 2009). However, for high tech products such as computers, possibilities for substitution toward lower GHG intensity of material use is very limited and therefore recycling, re-use and extended lifetimes are the only possibilities for consumers to reduce GHG intensity.

\subsubsection{Services}

For services, the range in GHG intensity is a bit lower compared to the other consumption categories. Energy related services of course provide the highest GHG intensity. Only the education and health sectors are close to the global GHG intensity target.

The emissions for services can be explained by the amount of foodstuffs, buildings, transportation or goods they use, directly or indirectly, since the life-cycle assessment (via the input-output method) includes the full supply chain accounting for monetary exchange of all the sectors. It is difficult to influence the inputs used to provide the different services. The only option to lower GHG intensity is to choose services with low energy and high labor costs (energy extensive and labor intensive). Like for goods, the potential of such shifts in consumption is in accordance with literature (Kok et al., 2006; Vringer and Blok, 1995), but because of the different functionalities of the services, the substitutability is limited.

\subsubsection{Power supply}

Power from fossil energy shows, not surprisingly, the highest GHG intensity. Biofuels show a large range in GHG intensity, while emissions from renewables or fossil with CCS are at least a factor of 5 lower compared to fossil fuels. Biofuels' GHG emissions are largely due to non-fossil $\mathrm{CO}_{2}$ emissions, especially from land use change. GHG intensity for fossil CCS power plants depends on the $\mathrm{CO}_{2}$ capture efficiency. The emissions for renewables stem from the fossil energy used in the production of their materials.

Consumers can directly choose renewable energy for shelter and their electric vehicle. These options are already considered in the respective categories. Here we would like to highlight the possible contribution of renewables in the other categories through consumer choice of products using renewable energies through the whole supply chain. Using renewable energy is technically possible and occurs in some cases for nearly all production and transportation processes. An exception is airfreight because, like for air travel, mitigation options are limited. The use of renewable energy in manufacturing would reduce GHG intensity below the RCP2.6 target for all vegetables, metals, plastics and all services except taxi driving. This can be seen from Fig. 2 by comparing the non-fossil GHG emissions with the GHG intensity target.

The strategy of using renewable power in manufacturing, shelter and transportation is in line with the global energy system models used for the RCP2.6 emission pathways, projecting the largest climate mitigation contribution for the power sector (van Vuuren et al., 2011b). An increasing potential of renewable energies is given without biofuels as well (IEA, 2012). Triggering the use of renewables from the consumption side is new but is already offered by some firms. According to a survey by the US national renewable energy laboratory (NREL), they identified 50 companies that advertise their products in the categories of food, goods and services as being made with renewable energy (Brannan et al., 2012). These companies communicate the use of renewable energy to the consumers through corporate branding initiatives or third party labels like "Green-e" or "wind made".

\subsection{Barriers to low GHG consumption}

The previous section showed that low GHG consumption options are available and consumption choices matter since the GHG intensity of consumption options within a consumption category can vary by more than tenfold. In this section we discuss how policy can support climate friendly product choices. We therefore first derive the main barriers to low GHG consumption from literature. Next, the relevance of these barriers to the low GHG consumption options is discussed. Finally, we indicate the role of policies to support low GHG consumption.

\subsubsection{Cost, preference, complexity and capital expenditure}

Findings from energy economics, behavioral economics and innovation studies point to relevant obstacles to the selection of low GHG consumption options. We have divided these in four categories: (1) consumer preferences, (2) higher total costs (including capital, maintenance and operation costs), (3) higher complexity and (4) higher capital expenditure.

The relevance of preferences and costs are postulated by standard economics (Becker, 1976), the relevance of the complexity of products is recognized by transaction cost economics (Williamson, 1979) and the underinvestment for capital intensive 
products results from behavioral economic theory such as loss aversion (Kahneman and Tversky, 1979). Behavioral economic findings such as heuristic decision making or bounded rationality further support product complexity and high capital costs as an indicator of adoption barriers (Sunstein, 2013). Furthermore, complexity, and especially high capital costs are found by energy economic research as being a cause of the non-diffusion of energy efficiency technologies despite their short payback times (Gillingham and Sweeney, 2012; Jaffe and Stavins, 1994). Finally, preference, costs and complexity can also be related to the five characteristics of innovations, which are recognized as determinants for the adoption rate by innovation research (Rogers, 2003). Here, cost refers to the "relative advantage" and preference to the compatibility of an innovation, while the complexity relates the remaining characteristics: simplicity, trialability and observability.

We limit the evaluation to the question of whether these indicators of barriers apply for some or most products and consumers. The consumer preference is operationalized by the past global trends in consumption. Costs refer to the price per functional unit, including all costs for the consumer over the product life cycle. The complexity is determined by the skills necessary to find and adopt a certain consumption option. This is in accordance with Dijksterhuis et al. (2006), who define complexity in the context of product choice as the amount of information a choice involves. The high capital expenditure only applies to products allowing lower maintenance and operation expenditure.

\subsubsection{Relevance of barriers to low GHG options}

The different low GHG options recognized in the previous section are listed against the possible barriers in Table 3. The justification of the existence of barriers is based on literature and described in detail in Table S2.

The consumer preference, indicated by the past global trend, is contrary to most options identified for food, as well as to the shift in travel mode toward lower GHG intensity. Globally, the share of meat and animal products is projected to further increase - only consumption of ruminant meat shows stabilization (FAO, 2006). Along with increasing air traffic (Girod et al., 2013c), the share of food transported by air can also be expected to increase. For mobility, the constant travel time budget drives the increasing use of faster travel modes and increasing income favors the use of cars (Schafer et al., 2010). Accordingly, global transportation models project an increasing shares of car and air travel (Girod et al., 2013c).
Interestingly only a few low GHG options have significantly higher total costs. Most pronounced are the higher costs for emobility (Dijk and Yarime, 2010). Renewable electricity results in higher manufacturing costs, however - as for electric cars - the distance from baseline prices is declining (IEA, 2012). For transportation the relative costs of low GHG options differ across countries. At least for some continental connections, public transport is more expensive than air travel.

Complexity is indicated to be important for most low GHG consumption categories. This is because, first, low GHG intensity options are often difficult to identify and, second, for energy services, the adoption of low GHG options requires additional skills. The information related complexity can be exemplified by food: while vegetable food is in general a low GHG choice, it has very high GHG intensity if transported by air or grown in a heated greenhouse (cf. Fig. 1). Without additional information, it is also nearly impossible to identify whether products are produced by renewable energy or made out of recycled material. Additional skills are required to correctly apply energy efficiency technologies in buildings (BPIE, 2011). These skills are, in general, beyond the capability of a typical household.

The capital expenditure barrier is relevant for all products with higher investment costs and lower running costs. This includes efficient buildings, building applied solar energy, appliances and electric cars, as well as products with higher quality and, therefore, lower lifetime or maintenance costs.

\subsubsection{Policies for low GHG consumption}

How can policy effectively address these barriers? There are various schools of thought on this topic. Standard economics suggest correction of market externalities. This would address options where cost or preference pose barriers by changing the utility per cost ratio, but would also contribute to overcoming the complexity and capital expenditure barriers. However, in the past, introduction of tax policies was not very successful. A review of the energy efficiency policies in the EU countries shows that, while only a few countries enacted environmental or climate taxes in the household sector, most countries introduced a mix of financial incentives, information campaigns, labels and standards (Schlomann and Eichhammer, 2012). This choice of measures is supported by findings from behavioral economics since they typically address behavioral market failures (Gillingham and Sweeney, 2012). In the following, we highlight examples of how policies like minimum standards, as well as nudges such as labels

Table 3

Indicator of barriers to low GHG intensity strategies regarding preference, costs, complexity or capital expenditure barriers.

\begin{tabular}{|c|c|c|c|c|}
\hline Low GHG intensity consumption option & Against consumer preferences ${ }^{a}$ & Higher total costs & Product complexity & Higher capital expenditure \\
\hline \multicolumn{5}{|l|}{ Food } \\
\hline Vegetal food & $\bullet$ & & 0 & \\
\hline Low GHG meat & $\bigcirc$ & & & \\
\hline Not by air or heated greenhouse & - & & O & \\
\hline \multicolumn{5}{|l|}{ Shelter } \\
\hline Energy eff. building & & & $\bullet$ & $\bullet$ \\
\hline Low GHG and renew. energy & & $\bullet$ & 0 & 0 \\
\hline Energy eff. appliance & & & - & - \\
\hline \multicolumn{5}{|l|}{ Travel } \\
\hline Mode shift & - & 0 & & \\
\hline E-mobility & & $\bullet$ & & - \\
\hline \multicolumn{5}{|l|}{ Goods and services } \\
\hline Re-cycle, re-use & & & $\bigcirc$ & \\
\hline Higher quality (longevity) & & 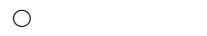 & $\bullet$ & $\bullet$ \\
\hline Energy extensive/labor intensive & & 0 & 0 & \\
\hline \multicolumn{5}{|l|}{ Cross-cutting } \\
\hline Made by RE & & $\bullet$ & $\bullet$ & \\
\hline
\end{tabular}

- Relevant for most products or consumer and $\bigcirc$ relevant for some products or consumers.

Note: For detailed justification of the barrier indicators see Table S2.

a Indicated by the past global trend. 
or defaults as proposed by Thaler and Sunstein (2008), can be effective in addressing the barriers to low GHG consumption. To realize the low GHG consumption potential identified above, these policies need to be improved and extended to all consumption categories and embodied emissions.

Default for low GHG consumption: Changing defaults can address search complexity, as well as influence preference and the willingness to pay for low GHG consumption with higher costs. After changing the default to a low GHG electricity mix, the most consumers do not opt out for a cheaper electricity mix with higher GHG intensity (Pichert and Katsikopoulos, 2008). A US public health study found that changing the default offer also allows preferences to be influenced (Hanks et al., 2012). This was evaluated by adjusting a lunch line in a cafeteria by offering healthier food options (which also included more vegetables), while the other line remained the same. Offering more healthy food increased its choice by $18 \%$; offering less unhealthy food decreased its choice by $28 \%$.

Labeling for low GHG consumption: Properly designed labels can address search complexity, higher capital expenditure and even higher total costs of low GHG options. A conjoint analysis with 150 participants on washing machines showed that consumers are willing to pay a 30\% higher price - which even exceeds the cost savings that can be expected over the life time of the product - if the product gets an A label. Besides providing labeling, the design of the label is also important as shown in experimental design (Newell and Siikamäki, 2013), but also as learned from practical experience (Sunstein, 2013).

Financial incentives for low GHG consumption: Financial incentives are an effective means to address high capital expenditure costs, higher total costs or product complexity. Stern (1999) shows in a review of financial incentives for proenvironmental consumer behavior that the size of the incentive, as well as its design, are relevant to the effect. For instance, the adoption of home weatherization measures in response to incentives is found to vary by a factor of 10 or more for the same incentive depending on program implementation (Stern, 2011). Stern reports the strength of program marketing, the accessibility of information on how to take advantage of the incentive and what benefits to expect are among the non-financial factors that account for this variation.

Standards for low GHG consumption: Mandatory energy efficiency standards are common for buildings but can also be used for appliances. For complex energy systems such as buildings, they are often formulated as a code and make detailed prescriptions concerning good practice in construction. These codes also include other aspects like health, noise avoidance or safety. The energy standards set the minimum energy efficiency level typically at cost-optimal level, considering long-term energy savings and investment costs. It is expected that such cost-optimal design will gradually converge to nearly zero energy standards (BPIE, 2011). Therefore energy efficiency standards and building codes can address the adoption complexity through the description of the building code and the high capital expenditure barrier by making a cost-optimal efficiency mandatory.

Incentive for selling low GHG consumption: Promoting low GHG consumption does not necessarily require policies directly addressing the consumer. Instead, policy can address the seller (e.g. utility, retailer). For instance, in Switzerland, car retailers need to achieve given average GHG intensities for the sold cars or else pay significant sanctions (Girod, 2012). This approach has an advantage in that sellers are often more flexible and more capable of nudging consumers toward low GHG consumption.

Regarding the policy recommendations, it is important to note that although the proposed measures can at least partially be justified by the non-optimality of current consumption choices, heuristic decision making (compared to optimization) can be more effective for the consumer in many decision situations because of limited information, time and processing capacity (Katsikopoulos, 2010). A complementary policy would therefore be to educate people to improve their decision heuristics as proposed by Bond (2009). For instance, learning or improving the heuristics for weighing future savings against initial capital expenditure would support the adoption of the many low GHG options confronted with the high capital expenditure barrier.

\subsection{Limitations and further research}

In this section, we discuss limitations along our main findings and derive avenues for further research on the potential for climate mitigation through changing consumption choices.

The identification of the illustrative low GHG consumption options is confirmed by comparison with studies from literature. However, additional and better life-cycle assessment data could be contributed for products produced in a clean supply chain (e.g. using renewables and energy efficient production). Here, product life-cycle assessment typically considers average industry data. Furthermore, for buildings, life-cycle assessment data is sparse compared to the other consumption categories. Still, current lifecycle assessment data was sufficient to draw a robust picture of the potential for choosing low GHG consumption options. A next research step could be to evaluate the required timing of low GHG options using models accounting for the inertia in the different consumption sectors.

The identification of low GHG options allowed barriers to low GHG consumption to be indicated. While this evaluation gave an overview of the potential for climate mitigation through changing consumption choices, further research in assessing barriers and policy implications is required. This is in support of the research from Dietz et al. (2009), which quantified the "behavioral plasticity" of selected low GHG options for US households in order to indicate the share that could adopt these options. Critical consumption options are those with low behavioral plasticity and high GHG intensity. This might be the case for air travel and (ruminant) meat consumption. Therefore, besides evaluating the behavioral plasticity of choices concerning high GHG options, research on the development of low GHG substitutes like in vitro meat (Tuomisto and de Mattos, 2011) and renewable (hydrogen) based airplanes (Ponater et al., 2006) is also required. On a more aggregated level, the shift in consumption would result in a major shift in the economy. This would potentially give firms and countries providing the low GHG product an advantage over the incumbents providing the default high GHG options. As a result, policies promoting low GHG options lack support and face institutional barriers reflecting the position of established interests (Unruh, 2000). However, the bottom-up approach of changing consumption (in contrast to top-down changes in production) could help to overcome this lock-in since low GHG options can evolve in market niches and the low GHG adopters can increase the required social pressure for institutional change (Unruh, 2002). Further research on the interdependencies between consumers, firms, and policy, as well as the effectiveness of different policy strategies in overcoming the multiple barriers to low GHG consumption, would help to improve the transition toward low GHG consumption.

To assess the full potential of changing behavior for climate mitigation, future research should go beyond the scope of this article and include related low GHG strategies outlined in Table 1 and their interrelation into a systematic evaluation. Finally, for the period after 2050, GHG intensities toward zero emissions are required. Here the development of radical innovations are important and require further research. 


\section{Conclusions}

In this study, we have evaluated the possible contribution of changes in consumption choices, defined as alternative selection of products within the five main consumption categories (food, shelter, travel, goods, services). We were able to identify consumption options that are in line with the $2^{\circ}$ target (RCP2.6) in all categories: for food, vegetal products not transported by air or grown in heated greenhouses; for shelter, houses with high efficiency through good insulation and especially through the use of renewable power; for travel, vehicles that can be connected to renewable power (battery electric cars and public road or rail transport, the latter achieving the lowest GHG intensity); and for goods, products based on energy extensive processes (e.g. wood, jute) or recycled materials. The relevance of consumption choices is revealed by the fact that, in all consumption categories, options with a GHG intensity a factor of ten above the lowest value options are available. The basket of low GHG consumption options widens when considering the possibility to produce these products by low and zero GHG emitting energy sources (such as renewables). This would add RCP2.6 compatible consumption options in all consumption categories.

The identification of specific low GHG options enables us to discuss the barriers to low GHG consumption in much more detail. Based on the literature we identified four categories of barriers: opposing preferences, higher costs, higher complexity and high investment costs. All low GHG consumption options are confronted with at least one of these barriers. The relevance of these barriers differs across the consumption categories and low GHG options. Hence, a 'one size fits all' policy is not likely to be effective for promoting a change in consumption choices. Instead, policies tailored to the different low GHG options are required. A discussion of consumer policies like defaults, labels, financial incentives and standards indicates that effective policy measures addressing the indicated barriers to low GHG consumption are available. A powerful lever for supporting low GHG consumption could be the expansion of the declaration of the source of electricity used in product manufacturing (e.g. "made by renewables" labels), which is only available for a few products today. Such a label would allow consumers to trigger changes in the power sector toward low and zero GHG emitting energy sources.

The implications for climate change mitigation from our work include the following. First, changing consumption has the potential to significantly contribute to reaching the RCP2.6 pathway; second, various barriers hinder the adoption of low GHG consumption options; third, effective policies to address these barriers are available but need to be tested, improved, and extended to all consumption categories and toward the inclusion of embodied emissions in order to tap this climate mitigation potential.

To improve the understanding of climate change mitigation through changing consumption, further research is needed by engineers and social scientists. Social scientists are required to study the behavioral plasticity of consumption choices toward low GHG consumption options in order to contribute to more effective policy design and indicate the limits in the substitutability. Engineers can also contribute to overcoming barriers by improving low GHG consumption options. In addition, they should focus on the development of low GHG alternatives for high GHG intensity products with limited substitutability, which certainly includes air travel and animal foodstuffs.

\section{Appendix A. Supplementary data}

Supplementary data associated with this article can be found, in the online version, at doi:10.1016/j.gloenvcha.2014.01.004.

\section{References}

Alfredsson, E.C., 2004. “Green” consumption-no solution for climate change. Energy 29, 513-524.

Allcott, H., Mullainathan, S., 2010. Behavior and energy policy. Science 327, $1204-$ 1205.

Becker, G.S., 1976. The Economic Approach to Human Behavoir. The University of Chicago Press, Chicago.

Blengini, G.A., 2009. Life cycle of buildings, demolition and recycling potential: a case study in Turin, Italy. Build. Environ. 44, 319-330.

Böhringer, C., Carbone, J.C., Rutherford, T.F., 2012. Unilateral climate policy design: efficiency and equity implications of alternative instruments to reduce carbon leakage. Energy Econ. 34, S208-S217.

Bojić, M., Nikolić, N., Nikolić, D., Skerlić, J., Miletić, I., 2011. Toward a positive-netenergy residential building in Serbian conditions. Appl. Energy 88, 2407-2419.

Bond, M., 2009. Risk school. Nature 461, 1189-1192.

BPIE, 2011. Europe's Buildings Under the Microscope. A Country-by-country Review of the Energy Performance of Buildings, Buildings. Buildings Performance Institute Europe, Brussel.

Brannan, D.B., Heeter, J., Bird, L., 2012. Made with Renewable Energy: How and Why Companies are Labeling Consumer Products, Colorado.

Carlsson-Kanyama, A., González, A.D., 2009. Potential contributions of food consumption patterns to climate change. Am. J. Clin. Nutr. 89, 1704S-1709S

Chester, M.V., Horvath, A., 2009. Environmental assessment of passenger transportation should include infrastructure and supply chains. Environ. Res. Lett. 4, 024008

Commoner, B.M., Corr, P.J.S., 1971. The Closing Circle: Nature, Man, and Technology Knopf, New York

Dahlstrøm, O., Sørnes, K., Eriksen, S.T., Hertwich, E.G., 2012. Life cycle assessment of a single-family residence built to either conventional- or passive house standard. Energy Build. 54, 470-479.

Damgaard, A., Larsen, A.W., Christensen, T.H., 2009. Recycling of metals: accounting of greenhouse gases and global warming contributions. Waste Manage. Res. 27, $773-780$.

de Vries, B., Bollen, J., Bouwman, L., den Elzen, M., Janssen, M., Kreileman, E., 2000 Greenhouse gas emissions in an equity- environment- and service-oriented world: an IMAGE-based scenario for the 21st century. Technol. Forecast. Soc. Change 63, 137-174.

Dettli, R., Baur, M., Philippen, D., Frischknecht, R., Emmenegger, M.F., 2006. Umweltwirkungen von Energiestandards - Perspektiven für den Gebäudepark Schweiz, Bern.

Dietz, T., Gardner, G.T., Gilligan, J., Stern, P.C., Vandenbergh, M.P., 2009. Household actions can provide a behavioral wedge to rapidly reduce US carbon emissions. Proc. Natl. Acad. Sci. U.S.A. 106, 18452-18456.

Dijk, M., Yarime, M., 2010. The emergence of hybrid-electric cars: innovation path creation through co-evolution of supply and demand. Technol. Forecast. Soc. Change 77, 1371-1390.

Dijksterhuis, A., Bos, M.W., Nordgren, L.F., van Baaren, R.B., 2006. On making the right choice: the deliberation-without-attention effect. Science 311, 1005-1007.

Ehrlich, P.R., Holdren, J.P., Series, N., Mar, N., 1971. Impact of population growth. Science 171, 1212-1217.

FAO, 2006. World Agriculture: Towards 2030/2050. Prospects for Food, Nutrition, Agriculture and Major Commodity Groups. EarthScan, London.

Frischknecht, R., Rebitzer, G., 2005. The ecoinvent database system: a comprehensive web-based LCA database. J. Clean. Prod. 13, 1337-1343.

Gillingham, K., Sweeney, J., 2012. Barriers to implementing low-carbon technologies. Clim. Chang. Econ. 3, 1250019.

Girod, B., 2012. Low carbon society in Switzerland: challenges and strategies. In: Herring, H. (Ed.), Living in a Low Carbon Society in 2050. Palgrave Macmillan, Hampshire.

Girod, B., de Haan, P., 2010. More or better? A model for changes in household greenhouse gas emissions due to higher income. J. Ind. Ecol. 14, 31-49.

Girod, B., van Vuuren, D.P., de Vries, B., 2013a. Influence of travel behavior on global $\mathrm{CO}_{2}$ emissions. Transp. Res. A: Policy Pract. 50, 183-197.

Girod, B., van Vuuren, D.P., Deetman, S., 2012. Global travel within the $2^{\circ}$ climate target. Energy Policy 45, 152-166.

Girod, B., van Vuuren, D.P., Hertwich, E.G., 2013b. Global climate targets and future consumption level: an evaluation of the required GHG intensity. Environ. Res. Lett. 8, 014016

Girod, B., Vuuren, D.P., Grahn, M., Kitous, A., Kim, S.H., Kyle, P., 2013c. Climate impact of transportation A model comparison. Clim. Change 118, 595-608.

González, A.D., Frostell, B., Carlsson-Kanyama, A., 2011. Protein efficiency per unit energy and per unit greenhouse gas emissions: potential contribution of diet choices to climate change mitigation. Food Policy 36, 562-570.

Hanks, A.S., Just, D.R., Smith, L.E., Wansink, B., 2012. Healthy convenience: nudging students toward healthier choices in the lunchroom. J. Public Health (Oxf.) 34 , $370-376$.

Harvey, L.D.D., 2009. Reducing energy use in the buildings sector: measures, costs, and examples. Energy Effic. 2, 139-163.

Hawkins, T.R., Singh, B., Majeau-Bettez, G., Strømman, A.H., 2013. Comparative environmental life cycle assessment of conventional and electric vehicles. J. Ind. Ecol. 17, 53-64.

Hendrickson, C., Horvath, A., Joshi, S., Lave, L., 1998. Economic Input-Output Models for Environmental Life-cycle Assessment. American Chemical Society Washington, DC, USA.

IEA, 2012. Energy Technology Perspectives 2012 Pathways to a Clean Energy System. International Energy Agency (IEA), Paris. 
IIASA, 2012. Energy end-use: buildings. In: Global Energy Assessment - Toward a Sustainable Future. Cambridge University Press, Cambridge, UK.

IPCC, 2000. Special Report on Emissions Scenarios. Cambridge University Press, Geneva.

Isaac, M., van Vuuren, D.P., 2009. Modeling global residential sector energy demand for heating and air conditioning in the context of climate change. Energy Policy 37, 507-521.

ISO, 2006. Environmental Management - Life Cycle Assessment - Requirements and Guidelines 14040. International Standards Organization, Geneva.

Jackson, T., 2009. Beyond the growth economy. J. Ind. Ecol. 13, 487-490.

Jacobs, M., 2012. Deadline 2015. Nature 481, 1371-1438.

Jaffe, A.B., Stavins, R.N., 1994. The energy-efficiency gap - what does it mean? Energy Policy 22, 804-810.

Kahneman, D., Tversky, A., 1979. Prospect theory: an analysis of decision under risk Econometrica 47, 291.

Katsikopoulos, K.V., 2010. Psychological heuristics for making inferences: definition, performance, and the emerging theory and practice. Decision Anal. 8, $1-24$.

Kok, R., Benders, R.M.J., Moll, H.C., 2006. Measuring the environmental load of household consumption using some methods based on input-output energy analysis: a comparison of methods and a discussion of results. Energy Policy 34, 2744-2761.

Larsen, H.N., Hertwich, E.G., 2009. The case for consumption-based accounting of greenhouse gas emissions to promote local climate action. Environ. Sci. Policy 12, 791-798.

Lovell, H., Bulkeley, H., Liverman, D., 2009. Carbon offsetting: sustaining consumption? Environ. Plan. A 41, 2357-2379.

Meinshausen, M., Smith, S.J., Calvin, K., Daniel, J.S., Kainuma, M.L.T., 2011. The RCP greenhouse gas concentrations and their extensions from 1765 to 2300. Clim. Change 109, 213-241.

Newell, R.G., Siikamäki, J.V., 2013. Nudging energy efficiency behavoir: the role of information labels. NBER Work. Pap. Ser.

Nielsen, P., Nielsen, A., Weidem, B., Dalgaard, R., Halberg, N., 2003. LCA food data base [WWW Document]. www.lcafood.dk.

OECD, 2007. The Political Economy of Environmentally Related Taxes, The Political Economy of Environmentally Related Taxes. OECD Publishing, Paris.

OECD, 2011. Environmental Outlook. OECD, Paris.

Peters, G.P., Hertwich, E.G., 2006. The importance of imports for household environmental impacts. J. Ind. Ecol. 10, 89-109.

Peters, G.P., Hertwich, E.G., 2008. Post-Kyoto greenhouse gas inventories: production versus consumption. Clim. Change 86, 51-66.

Pichert, D., Katsikopoulos, K.V., 2008. Green defaults: Information presentation and pro-environmental behaviour. J. Environ. Psychol. 28, 63-73.

Ponater, M., Pechtl, S., Sausen, R., Schumann, U., Hüttig, G., 2006. Potential of the cryoplane technology to reduce aircraft climate impact: a state-of-the-art assessment. Atmos. Environ. 40, 6928-6944.

Rogers, E.M., 2003. Diffusion of Innovations, 5th ed. Free Press, New York.

Ross, S., Evans, D., 2003. The environmental effect of reusing and recycling a plasticbased packaging system. J. Clean. Prod. 11, 561-571.

Schafer, A., Heywood, J., Jacoby, H., Waitz, I., 2010. Transportation in a Climateconstrained World. MIT Press, Massachusetts.

Schlomann, B., Eichhammer, W., 2012. Energy Efficiency Policies in the European Union in the EU. Fraunhofer ISI, Karlsruhe.

Schnoor, J.L., 2012. Coalitions of the willing. Environ. Sci. Technol. 46, 9201.
Spielmann, M., Scholz, R.W., 2005. Life cycle inventories of transport services. Int. J. Life Cycle Assess. 10, 85-94.

Stehfest, E., Bouwman, L., Vuuren, D.P., Elzen, M.G.J., Eickhout, B., Kabat, P., 2009a. Climate benefits of changing diet. Clim. Change 95, 83-102.

Stehfest, E., Bouwman, L., Vuuren, D.P., Van Elzen, M.G.J., Den Eickhout, B., Kabat, P., 2009b. Climate benefits of changing diet. Clim. Change 95, 83-102.

Stern, P.C., 1999. Information, incentives, and proenvironmental consumer behavoir. J. Consum. Policy 22, 461-478.

Stern, P.C., 2011. Contributions of psychology to limiting climate change. Am. Psychol. 66, 303-314.

Suh, S., 2005. Developing a sectoral environmental database for input-output analysis: the comprehensive environmental data archive of the US. Econ. Syst. Res. 17, 449-469.

Sulston, J., Bateson, P., Biggar, N., Fang, C., Cavenaghi, S., Cleland, J., Cohen, J., Dasgupta, P., Eloundou-Enyegue, P.M., Fitter, A., Habte, D., Harper, S., Jackson, T., Mace, G., Owens, S., Porritt, J., Bixby, M.P., Pretty, J., Ram, F., Short, R., Spencer, S., Xiaoying, Z., Zulu, E., 2012. People and the Planet. Royal Society, London.

Sunstein, C.R., 2013. Simpler: The Future of Government. Simon \& Schuster, New York.

Thaler, R.H., Sunstein, C.R., 2008. Nudge: Improving Decisions about Health, Wealth and Happiness. Yale University Press, New Haven.

Thormark, C., 2006. The effect of material choice on the total energy need and recycling potential of a building. Build. Environ. 41, 1019-1026.

Tobler, C., Visschers, V.H.M., Siegrist, M., 2012. Addressing climate change: determinants of consumers 'willingness to act and to support policy measures. J. Environ. Psychol. 32, 197-207.

Tuomisto, H.L., de Mattos, M.J.T., 2011. Environmental impacts of cultured meat production. Environ. Sci. Technol. 45, 6117-6123.

UN, 2009. World Population Prospects: The 2008 Revision Population Database.

UN, 2011. Cancun Agreement. Cancun.

Unruh, G.C., 2000. Understanding carbon lock-in. Energy Policy 28, 817-830.

Unruh, G.C., 2002. Escaping carbon lock-in. Energy Policy 30, 317-325.

Van Ruijven, B., de Vries, B., van Vuuren, D.P., van der Sluijs, J.P., 2010. A global model for residential energy use: uncertainty in calibration to regional data. Energy 35, 269-282.

Van Vuuren, D.P., Edmonds, J., Kainuma, M., Riahi, K., Thomson, A., Hibbard, K., Hurtt, G., Kram, T., Krey, V., Lamarque, J.-F., Masui, T., Meinshausen, M. Nakicenovic, N., Smith, S., Rose, S., 2011a. The representative concentration pathways: an overview. Clim. Change 109, 5-31.

Van Vuuren, D.P., Stehfest, E., Elzen, M.G.J., Kram, T., Vliet, J., Deetman, S., Isaac, M., Klein Goldewijk, K., Hof, A., Mendoza Beltran, A., Oostenrijk, R., Ruijven, B. 2011b. RCP2.6: exploring the possibility to keep global mean temperature increase below $2^{\circ} \mathrm{C}$. Clim. Change 109, 95-116.

Vringer, K., Blok, K., 1995. The direct and indirect energy-requirements of households in the Netherlands. Energy Policy 23, 893-902.

Vuuren, D.P., van Edmonds, J., Kainuma, M., Riahi, K., Thomson, A., Hibbard, K., Hurtt, G.C., Kram, T., Krey, V., Lamarque, J.-F., Matsui, T., Meinshausen, M., Nakicenovic, N., Rose, S.K., 2011. The representative concentration pathways: an overview. Clim. Change 109, 5-31.

Williamson, O.E., 1979. Transaction-cost economics: the governance of contractual relations. Chicago J. 22, 233-261.

Wilson, C., Grubler, A., Gallagher, K.S., Nemet, G.F., 2012. Marginalization of end-use technologies in energy innovation for climate protection. Nat. Clim. Chang. 2, 780-788. 